\title{
TEMPAT BEKERJA DAN TINGGAL UNTUK KAUM MILENIAL
}

\author{
Arvian $^{1)}$, Rudy Surya ${ }^{2)}$ \\ 1)Program Studi S1 Arsitektur, Fakultas Teknik, Universitas Tarumanagara, arvian_sutanto@yahoo.com \\ 2) Program Studi S1 Arsitektur, Fakultas Teknik, Universitas Tarumanagara, rudys@ft.untar.ac.id
}

\begin{abstract}
Abstrak
Permasalahan tentang stress terhadap Generasi Milenial di Jakarta yang di sebabkan oleh masalah ruang kerja yang konvensional dan juga masalah commuter sudah sangat banyak. Namun belum ada solusi yang baik terhadap penyelesaian masalah tersebut. Karena itu penelitian ini memilih sebuah fasilitas Co-Living. Penelitian ini bertujuan untuk menghasilkan ruang sensual yang dapat membawa atmosfer pengguna fasilitas mendapatkan perasaan yang cocok untuk melakukan aktivitas. Penelitian ini menggunakan metode tipologi literatur tentang psikologi keruangan dan dimensi - dimensi arsitektural yang mempengaruhi indera manusia di dalam sebuah ruang. Fasilitas Co-Living ini meliputi fasilitas Co-Living area untuk menjadi solusi bagi para commuter yang tinggal jauh atau ingin mendapat tempat istirahat sementara yang murah dan terjangkau. Co-Working Space untuk Generasi Milenial yang ingin memiliki start-up atau sekerdar menjadi tempat untuk beraktifitas bersama. Learning Center untuk memenuhi kebutuhan mereka yang ingin mempelajari soft-skill tertentu untuk memenuhi skill masing - masing setiap individu. Pada setiap ruang juga memperhatikan elemen - elemen arsitektural lainnya seperti material dan pencahayaan.
\end{abstract}

Kata kunci: area belajar; millenial; tempat belajar; tempat tinggal

\begin{abstract}
The problem of stress on the Generation of Milenial in Jakarta which is caused by the problems of conventional work space and also the problem of commuter has been very much. But there is no good solution to solving the problem. Therefore this study chose a Co-Living facility. This study aims to produce sensual space that can bring the atmosphere of facility users to get a feeling that is suitable for doing activities. This study uses a literature typology method on spatial psychology and architectural dimensions that affect the human senses in a space. This Co-Living facility includes Co-Living area facilities to be a solution for Commuters who live far away or want to get a cheap and affordable temporary resting place. Co-Working Space for Generations of Milenial who want to have a start-up or even become a place to do activities together. Learning Center to meet the needs of those who want to learn certain soft skills to fulfill each individual's skills. Each room also concerns other architectural elements such as material and lighting.
\end{abstract}

Keywords: milenial; place to study residence; study area

\section{PENDAHULUAN}

DKI Jakarta, Ibu kota negara dan kota dengan perputaran ekonomi terbesar di Indonesia, tak lepas dari berbagai permasalahan yang timbul akibat modernisasi dan perkembangan industri. Salah satu penyebab dari modernisasi dan perkembangan industri adalah perubahan zaman dan juga ilmu pengetahuan yang selalu menghasilkan penemuan baru dan membuat dunia kita menjadi lebih mudah dan lebih cepat menuju perkembangan zaman itu sendiri.

Generasi Milenials merupakan pengerak dari faktor modernisasi tersebut. Generasi milenial merupakan mereka yang lahir pada tahun 1980 hingga 2000. Data menyebutkan sekitar 80\% generasi milenials mengakses media sosial setiap hari. Mereka biasanya mencari informasi seperti hiburan, liburan, kuliner, olahraga, politik, serta pendidikan.

Di era ini, era yang sering disebut sebagai eranya generasi millennial dimana generasi yang terdiri dari pemuda kelahiran 90-an. Di mana pemuda generasi saat ini tidak aktif dan bersuara 
di lingkungan secara langsung melainkan aktif dan hanya bias berkomentar di social media. Kita berada dimana pemuda lebih memilih menyalurkan suaranya melalui media sosial melainkan ikut turun langsung kejalan. Karena kecenderungan itu, seakan membuat generasi pemuda saat ini membuat 'tembok' pembatas pada dirinya sendiri dan lingkungan sekitar.

Memasuki tahun 2020, bangsa Indonesia di perkirakan akan mengalami lonjakan jumlah penduduk usia produktif. Pertama kali dalam sejarah bangsa Indonesia lonjakan tersebut akan membentuk proporsi yang biasa kita sebut sebagai bonus demografi. Bagi generasi millennial fenomena ini merupakan sebuah tantangan yang harus di hadapi dengan optimis untuk mewujudkan kemandirian bangsa dalam segala aspek. Menurut prediksi, fenomena bonus demografi akan mencapai puncaknya pada tahun 2020-2030. Pada periode tersebut, sebanyak $70 \%$ penduduk berada pada usia produktif.

Generasi millenials memiliki peluang dan kesempatan berinovasi yang sangat luas dan besar di era ini. Terciptanya ekosistem digital berhasil menciptakan beraneka ragam bidang usaha tumbuh menjamur di Indonesia. Hal ini dapat kita lihat dari munculnya berbagai start up digital mulai dari gojek, tokopedia, bukalapak.com, dan shopee.

Oleh karena itu generasi millenials ini adalah modah besar untuk mewujudkan kemandirian bangsa dalam segala aspek tersebut. Maka dari itu Arsitektur harus menangapi perkembangan tersebut dengan tujuan membantu dan mendorong generasi muda ini agar dapat menjadi genererasi yang dapat menjadi pemaju dan penerus bangsa demi menciptakan bangsa Indonesia yang mandiri dan kedepan di masa yang akan datang.

\section{KAJIAN LITERATUR}

\section{Pengertian Lingkungan Kerja}

Bahwa lingkungan kerja adalah segala sesuatu yang ada disekitar para pekerja/karyawan yang dapat mempengaruhi kepuasan kerja karywan dalam melaksanakan pekerjaannya sehingga akan diperoleh hasil kerja yang maksimal, dimana dalam lingkungan kerja tersebut terdapat fasilitas kerja yang mendukung karyawan dalam penyelesaian tugas yang bebankan kepada karyawan guna meningkatkan kerja karyawan dalam suatu perusahaan.

\section{Faktor-Faktor yang Mempengaruhi Lingkungan Kerja}

Untuk menciptakan lingkungan kerja yang baik ada beberapa hal yang harus diperhatikan yaitu (Siagian, 2006:63) :

- Bangunan tempat kerja

- Ruang kerja yang lega

- Ventilasi pertukaran udara

- Tersedianya tempat-tempat ibadah keagamaan

- Tersedianya sarana angkutan khusus maupun umum yang nyaman dan murah untuk masyarakat sekitar

Menurut (Sedarmayanti dalam Wulan, 2011:21) Menyatakan bahwa secara garis besar, jenis lingkungan kerja terbagi menjadi dua faktor yaitu faktor lingkungan kerja fisik dan faktor lingkungan kerja non fisik.

(1) Faktor lingkungan kerja fisik

- Pewarnaan

- Penerangan

- Udara

- Suara bising

- Ruang gerak

- Keamanan

- Kebersihan

(2) Faktor lingkungan kerja non-fisik

- Struktur kerja 
- Tanggung jawab kerja

- Perhatian dan dukungan pemimpin

- Kerja sama antar kelompok

- Kelancaran komunikasi

Menurut (Suwatno dan Priansa, 2011:163) secara umum lingkungan kerja terdiri dari lingkungan kerja fisik dan lingkungan kerja psikis.

(1) Faktor Lingkungan Fisik

Faktor lingkungan fisik adalah lingkungan yang berada disekitar pekerja itu sndiri. Kondisi di lingkungan kerja dapat mempengaruhi kepuasan kerja karyawan yang meliputi:

(a) Rencana Ruang Kerja

Meliputi kesesuaian pengaturan dan tata letak peralatan kerja, hal ini berpengaruh besar terhadap kenyamanan dan tampilan kerja karyawan.

(b) Rancangan Pekerjaan

Meliputi peralatan kerja dan prosedur kerja atau metode kerja, peralatan kerja yang tidak sesuai dengan pekerjaannya akan mempengaruhi kesehatan hasil kerja karywan.

(c) Kondisi Lingkungan Kerja

Penerangan dan kebisingan sangat berhubungan dengan kenyamanan para pekerja dalam bekerja. Sirkulasi udara, suhu ruangan dan penerangan yang sesuai sangat mempengaruhi kondisi seseorang dalam menjalankan tugasnya.

(d) Tingkat Visual Privacy dan Acoustical Privacy

Dalam tingkat pekerjaan tertentu membutuhkan tempat kerja yang dapat mdemberi privasi bagi karyawannya. Yang dimaksud privasi disini adalah sebagai "keleluasan pribadi " terhadapa hal-hal yang menyangkut dirinya dan kelompoknya. Sedangkan acoustical privasi berhubungan dengan pendengaran.

(2) Faktor Lingkungan Psikis

Faktor lingkungan psikis adalah hal-hal yang menyangkut dengan hubungan sosial dan keorganisasian. Kondisi psikis yang mempengaruhi kepuasan kerja karyawan adalah:

(a) Pekerjaan Yang Berlebihan

Pekerjaan yang berlebihan dengan waktu yang terbatas atau mendesak dalam penyelesaian suatu pekerjaan akan menimbulkan penekanan dan ketegangan terhadap karyawan, sehingga hasil yang didapat kurang maksimal.

(b) Sistem Pengawasan Yang Buruk

Sistem pengawasan yang buruk dan tidak efisien dapat menimbulkan ketidak puasaan lainnya, seperti ketidak stabilan suasana politik dan kurangnya umpan balik prestasi kerja.

(c) Frustasi

Frustasi dapatberdampak pada terhambatnya usaha pencapaian tujuan, misalnya harapan perusahaan tidak sesuai dengan harapan karyawan, apanbila hal ini berlangsung terus menerus akan menimbulkan frustasi bagi karyawan.

(d) Perubahan-Perubahan Dalam Segala Bentuk

Perubahan yang terjadi dalam pekerjaaan akan mempengaruhi cara orang-orang dalam bekerja, misalnya perubahan lingkungan kerja seperti perubahan jenis pekerjaan, perubahan organisasi, dan pergantian pemimpin perusahaan.

(e) Perselisihan Antara Pribadi Dan Kelompok

Hal ini terjadi apabila kedua belah pihak mempunyai tujuan yang sama dan bersaing untuk mencapai tujuan tersebut. Perselisihan inin dapat berdampak negatif yaitu terjadinya peselisihan dalam berkomunikasi, kurangnya kekompakan dan kerjasama. Sedangkan dampak positifnya adalah adanya usaha positif untuk 
mengatasiperselisihan ditempat kerja, diantaranya: persaingan, masalah status dan perbedaan antara individu.

Lingkungan kerja fisik maupun psikis keduanya sama pentingnya dalam sebuah organisasi, kedua lingkungan kerja ini tidak bisa dipisahkan. Apabila sebuah perusahaan hanya mengutamakan satu jenis lingkungan kerja saja, tidak akan tercipta lingkungan kerja yang baik, dan lingkungan kerja yang kurang baik dapat menuntut tenaga kerja dan waktu yang lebih banyak dan tidak mendukung diperolehnya rancangan sistem kerja yang efisien dan akan menyebabkan perusahaan tersebut mengalami penurunan produktivitas kerja.

\section{Aspek Lingkungan Kerja}

Lingkungan kerja dapat dibagi menjadi beberapa bagian atau bisa disebut juga aspek pembentuk lingkungan kerja, bagian-bagian itu bisa diuraikan sebagai berikut (Simanjuntak, 2003:39):

(1) Pelayanan kerja

Pelayanan karyawan merupakan aspek terpenting yang harus dilakukan oleh setiap perusahaan terhadap tenaga kerja. Pelayanan yang baik dari perusahaan akan membuat karyawan lebih bergairah dalam bekerja, mempunyai rasa tanggung jawab dalam menyelesaikan pekerjaannnya, serta dapat terus mennjaga nama baik perusahaan melalui produktivitas kerjanya dan tingkah lakuknya. Pada umumnya pelayanan karyawan meliputi beberapa hal yakni :

(a) Pelayanan makan dan minum.

(b) Pelayanan kesehatan .

(c) Pelayanan kamar kecil/kamar mandi ditempat kerja, dan sebagainya.

(2) Kondisi Kerja

Kondisi kerja karyawan sebaiknya diusahakan oleh manajemen perusahaan sebaik mungkin agar timbul rasa aman dalam bekerja untuk karyawannya, kondisi kerja ini meliputi penerangan yang cukup, suhu udara yang tepat, kebisingan yang ddapat dikendalikan, pengaruh warna, runag gerak yang diperlukan dan keamanan kerja karyawan.

(3) Hubungan karyawan

Hubungan karyawan akan sangat menentukan dalam menghasilkan produktivitas kerja. Hala ini disebabkan karena adanya hubungan antara motivasi serta semangat dan kegairahan kerja dengan hubungan yang kondusif antar sesama karyawan dalam bekerja, ketidak serasian hubungan antara karyawan dapat menurunkan motivasi dan kegairahan yang akibatnya akan dapat menurunkan produktivitas kerja.

\section{Indikator Lingkungan Kerja}

Adapun indikator lingkungan kerja menurut (Sedarmayanti: 2004:46) adalah sebagai berikut:

(1) Penerangan / cahaya di tempat kerja

(2) Tempetratur / suhu udara di tempat kerja

(3) Kelembapan udara di tempat kerja

(4) Sirkulasi udara di tempat kerja

(5) Getaran mekanis di tempat kerja

(6) Bau tidak sedap di tempat kerja

(7) Tata warna di tempat kerja

(8) Dekorasi di tempat kerja

(9) Music di tempat kerja

(10)Keamanan di tempat kerja 
Untuk dapat menciptakan lingkungan kerja yang efektif dalam perusahaan ada beberapa faktor yang perlu diperhatikan (Gie dalam Nuraini: 2013:103):

(1) Cahaya

Cahaya penerangan yang cukup memancarkan dengan tepat akan menambah efisiensi kerja para karyawan/pegawai, karna mereka dapat bekerja dengan lebih cepat lebih sedikit membuat kesalahan dan matanya tak lekas menjadi lelah.

(2) Warna

Warna merupakan salah satu faktor yang penting untuk memperbesar efisiensi kerja para karyawan, khususnya warna akan mempengaruhi keadaan jiwa mereka dengan memakai warna yang tepat 19 pada dinding ruang dan alat-alat lainnya kegembiraan dan ketenangan bekerja para karyawan akan terpelihara.

(3) Udara

Mengenai faktor udara ini, yang sering sekali adalah suhu udara dan banyaknya uap air pada udara itu.

(4) Suara

Untuk mengatasi terjadinya kegaduhan, perlu kiranya meletakkan alat-alat yang memiliki suara yang keras, seperti mesin ketik pesawat telpon, parkir motor, dan lain-lain. Pada ruang khusus, sehongga tidak mengganggu pekerja lainnya dalam melaksanakan tugasnya.

\section{Manfaat Lingkungan Kerja}

Manfaat lingkungan kerja adalah menciptakan gairah kerja, sehingga produktivitas kerja meningkat. Sementara itu, manfaat yang diperoleh karena bekerja dengan orang-orang yang termotivasi adalah pekerjaan dapat diselesaikan dengan tepat. Artinya pekerjaan diselesaikan sesuai standar yang benar dan dalam skala waktu yang ditentukan. Kinerjanya akan dipantau oleh individu yang bersangkutan dan tidak akan membutuhkan terlalu banyak pengawasan serta semangat juangnya akan tinggi.(Arep, 2003:103).

\section{Generasi Millenial}

Millennial adalah istilah cohort dalam demografi, merupakan kata benda yang berarti pengikut atau kelompok. Saat ini ada empat cohort besar dalam demografi, yaitu Baby Boomer (lahir pada tahun 1946-1964), Gen-X (lahir pada tahun 1965-1980), Millennial (lahir pada tahun 1981-2000), dan Gen-Z (lahir pada tahun 2001-sekarang). Dalam literatur lain, Menurut Absher dan Amidjaya bahwa generasi millennial merupakan generasi yang lahirnya berkisar antara 1982 sampai dengan 2002, selisih yang tidak terlalu signifikan (Ali \& Lilik Purwandi, 2017, pp. 3,4) Generasi millennial saat ini (pada tahun 2017) adalah mereka yang berusia 17-36 tahun; mereka yang kini berperan sebagai mahasiswa, early jobber, dan orangtua muda; seperti Afgan, Raisa, Agnes Monica, dan Raffi Ahmad. Dewasa ini mereka adalah idola masyarakat dengan ciri khas musik yang agak mellow dan lirik selalu dibumbui percintaan dan kegalauan.

Menurut data BPS yang dikeluarkan pada tahun 2013, jumlah millennial Indonesia pada tahun 2015 diperkirakan mencapai 33\% dari total penduduk Indonesia. Artinya, total populasi millennial pada tahun 2015 mencapai 83 juta jiwa. Pada tahun 2020, proporsi millennial dapat mencapai 34\% yang akan berada pada usia 20 hingga 40 tahun. Pada tahun tersebut, generasi millennial akan menjadi tulang punggung perekonomian Indonesia karena mulai berkurangnya populasi Gen-X dan Baby Boomer. Dengan demikian, terjadilah bonus demografi. Populasi millennial terbanyak berada di pulau Jawa yang diperkirakan pada tahun 2015 ada 47 juta jiwa. (Ali \& Lilik Purwandi, 2017, pp. 8-11). 
Generasi dalam era millennial ini seperti: google generation, net generation, echo boomers, dan dumbest generation. Oleh karena itu, masyarakat generasi millennial itu bisa ditandai dengan meningkatnya penggunaan alat komunikasi, media dan teknologi informasi yang digunakan. Misalnya: internet, MP3 player, youtube, facebook, instagram dan lain sebagainya. Generasi millennial merupakan inovator, karena mereka mencari, belajar dan bekerja di dalam lingkungan inovasi yang sangat mengandalkan teknologi untuk melakukan perubahan di dalam berbagai aspek kehidupannya. (Endang Fatmawati, 2010).

Hasanuddin Ali dan Lilik Purwandi menyimpulkan bahwa masyarakat Urban MiddleClass Millennial memiliki tiga karakter utama, yaitu 3C; connected, creative, dan confidence. Pertama, connected. Generasi millennial adalah pribadi yang pandai bersosialisasi, terutama dalam komunitas yang mereka ikuti serta berkelana di media sosial. Kedua, creative. Mereka adalah orang yang biasa berpikir out of the box, kaya akan ide dan gagasan serta mampu mengomunikasikannya secara cemerlang yang dibuktikan dengan tumbuhnya industri yang dimotori oleh anak muda. Ketiga, confidence. Mereka merupakan orang yang percaya diri, berani mengungkapkan pendapat, serta tidak sungkan berdebat di depan publik, seperti yang terjadi di media sosial. Lihat gambar 1. (Ali \& Lilik Purwandi, 2017, pp. 83-4)

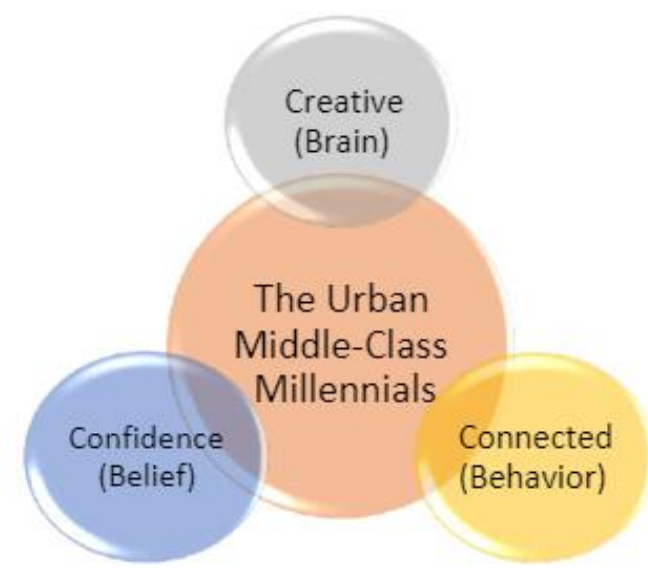

Gambar 1. Bubble Diagram Urban Middle-Class Milenial Sumber: Penulis, 2019

\section{Konsep Kerja Generasi Millenials}

Generasi millennial awalnya tumbuh dengan pikiran suasana bekerja yang mengerikan. Hingga akhirnya beranjak dewasa, generasi ini mulai menciptakan sesuatu yang baru agar apa yang terpikirkan selama ini tak terulang pada mereka. Karena itu, generasi millenial berusaha membuat iklim kantor yang menyenangkan. Menghilangkan beberapa peraturan dan nyaris tanpa peraturan yang mengikat.

Survei yang dilakukan oleh The American Institute of Stress bisa menjadi bukti betapa menakutkannya tempat kerja. Data menyebutkan bahwa 46 persen penyebab stress erat kaitannya dengan suatu pekerjaan dan tempat kerja itu sendiri. Lebih parah lagi survei lembaga Integra yang mengatakan bahwa 65 persen pekerja stress di tempat kerja dan membuat hidup tambah berat.

Dulu kantor adalah momok yang menakutkan dengan segala peraturan yang mengekang. Datang ke kantor wajib pukul 9 pagi. Setiap hari wajib mengenakan outfit formal seperti sepatu pantofel dan pakaian formal. Belum lagi dengan aturan jatah cuti yang ketat, atau bahkan sekat-sekat meja kerja yang membuat hidup terasa individual dalam kantor. Aturan semacam ini dianggap sangat menakutkan dan membuat hidup terasa menjadi beban. 
Salah satu kantor yang kerap jadi rujukan saat ini adalah Google. Dalam survei yang dilakukan oleh Fortune, perusahaan yang bermarkas di Mountain View, California ini tujuh kali menempati posisi teratas dan selalu masuk dalam sepuluh survei terakhir sebagai tempat kerja terbaik di dunia.

Dalam berbagai wawancara dengan pekerja Google, mereka kerap mengatakan bahwa Google adalah tempat yang menghargai karyawan. Memanusiakan karyawan sebagai manusia bukan sebagai sekrup dalam mesin. Google juga dilengkapi dengan fasilitas yang mengagumkan, kopi yang enak, klinik kesehatan, kelas fitness, tempat tidur, tempat potong rambut, hingga laundri gratis. belum lagi ditambah dengan kudapan tidak terbatas dan tiga kali jatah makanan organik dalam sehari.

Tak salah bila Billy McMahon dan Nick Campbell dalam film The Internship mengataskan Google seperti taman hiburan besar yang berjuta-juta kali lebih bagus.

Selain Google, ada beberapa tempat kerja lain yang menerapkan sistem kerja fleksibel. Mereka punya suasana kerja menyenangkan sebagaimana Google. Antara lain Airbnb, Boston Consulting Group, Facebook, LinkedIn, Guidewire, hingga Netflix.

\section{Tempat yang nyaman untuk bekerja bagi Milenial}

Generasi milenial menguasai teknologi. Kalaupun tidak, mereka akan belajar melalui berbagai informasi agar bisa mahir menggunakannya. Generasi milenial punya daya imajinasi dan kreatif serta terampil memecahkan masalah. Generasi ini dibesarkan dengan kalimatkalimat semacam "You can do anything" dan "Nothing is imposible" karena itu mereka cenderung punya daya saing yang tinggi dan percaya diri yang juga tinggi.

Generasi milenial selalu terhubung dengan orang-orang di angkatannya melalui banyak cara, salah satunya melalui media sosial. Mereka terbiasa bekerja sama dengan orang-orang dari latar belakang berbeda. Pikiran mereka tidak terbelenggu stereotip.

Hal tersebut sangat mempengaruhi lingkungan kerja di Generasi Milenial. Dengan keadaan seperti itu mereka lebih cenderung memilih berada di lingkungan kerja yang membuat mereka tidak stress dan dapat membuat mudah berpikir. Tempat kerja yang nayaman menurut mereka bukan tempat kerja yang konvensional seperti tipologi kantor yang ada saat ini melainkan lebih memiliki tipologi tempat kerja yang memiliki campuran terhadap area bekerja dan area untuk duduk santai seperti memiliki kesan sendang berada dicafe atau berada di luat kantor seperti pada umumnya. Dengan lingkungan seperti itulah para generasi millennial lebih nyaman dalam bekerja karena terdapat transparansi kenyamanan ruang dan juga relasi antara pekerja lainnya.

\section{METODE (11pt)}

Untuk membantu proses perancangan fasilitas Co-Living for Milenial di Kawasan Jakarta, dibutuhkan metode perancangan yang menentukan arah analisis dan perancangan. Analisa untuk memahami pola kehidupan Generasi Milenial dan juga para commuter, secara mendalam dilakukan secara kualitatif dan pragmatis. Sedangkan untuk perancangan digunakan analisis data yang sudah dikumpulkan dan menghasilkan sintesis yang akan dibentuk untuk menjadi hasil akhir.

Pencarian data berdasarkan metode kualitatif adalah sebuah metode penelitian yang deskriptif, dengan hasil berupa kata dan gambar, bukan angka. Metode kualitatif memperhatikan proses dan kejadian yang terjadi, bukan melihat produk akhir. Metode kualitatif juga berusaha untuk memahami suatu keadaan, bukan hanya melihat keadaan yang ada.

Dengan metode kualitatif, data yang terkumpul dari Kawasan Jakarta dan sekitarnya bersifat data primer dan data sekunder. Data primer adalah data yang diperoleh secara langsung dari sumber asli. Sedangkan data sekunder adalah data yang didapat secara tidak langsung, berisi tentang pencarian informasi mengenai hal yang di teliti. Data primer yang 
didapatkan di kawasan Jakarta, mempelajari mengenai kejadian yang terjadi di dalam suatu Kawasan kota yang padat secara ekonomi dan memperhatikan pergerakan para pekerja kantoran. Data sekunder yang didapat dari kawasan Jakarta dilakukan dengan cara pencarian data mengenai peraturan tapak, zonasi, berita mengenai kawasan Jakarta, regulasi daerah tempat hunian, dsb. Data sekunder diperoleh melalui media tertulis seperti artikel, koran, karya ilmiah, dan internet. Adapun langkah - langkah untuk mendapatkan data - data tersebut adalah sebagai berikut :

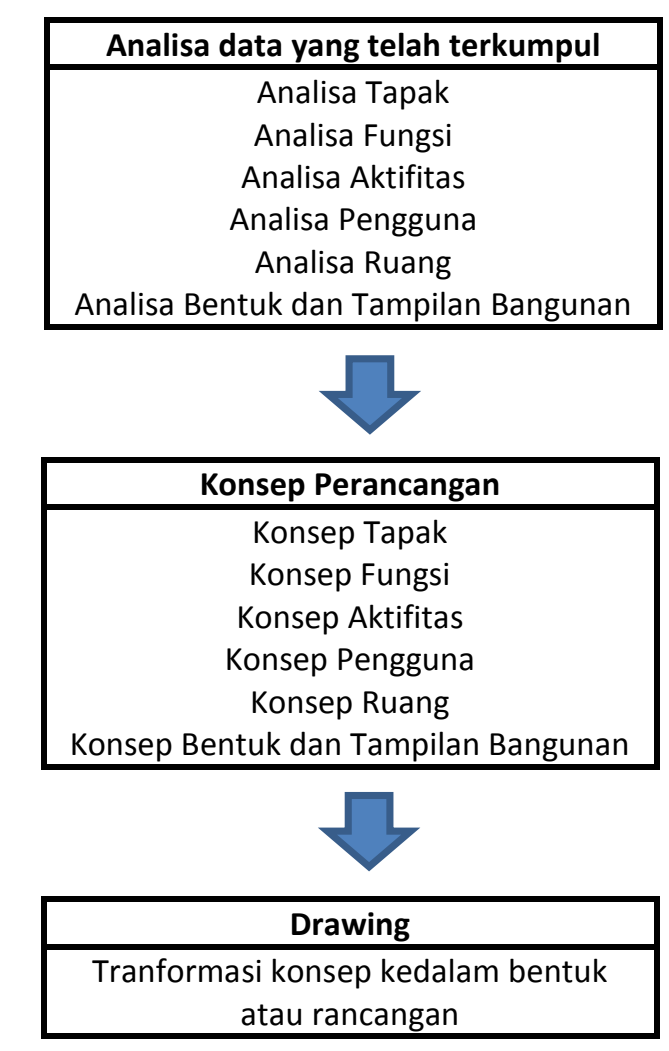

Gambar 2. Diagram Skema Proses Perancangan

Sumber: Penulis, 2019

\section{DISKUSI DAN HASIL}

Generasi millennial sangat terbiasa dengan fleksibel dan juga kemudahan. Hal ini sangat mempengaruhi cara kerja dan juga kebiasaan mereka saat bekerja, dengan memiliki kebiasaan yang fleksibel dan instan, Generasi Millennial cenderung tidak nyaman berada di ruang yang konvensional karena apa yang di rasakan mereka seperti berada di dalam sebuah penjara yang tidak dapat memiliki akses ke ruangan lain secara bebas dan kapan saja.

Bentuk ruang seperti gambar di bawah ini merupakan bentuk Tipologi kantor yang banyak berkembang sekarang, karena demi memenuhi efesiensi ruang, tetapi dengan Tipologi kantor seperti ini sangat tidak sesuai dengan kebiasaan Generasi Milenial. 

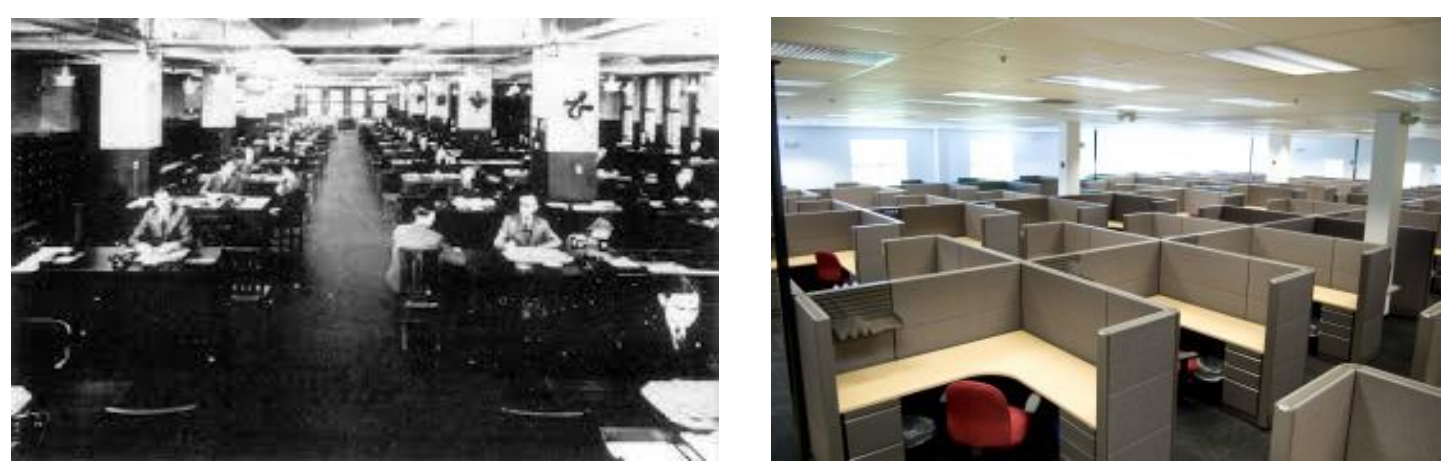

Gambar 3. Tipologi Kantor sebelum perang dunia II

cubicle kantor yang sering dijumpai

Sumber: https://www.ethosource.com/selecting-the-right-office-cubicle-layout.html

Maka dari itu, Generasi Milenial membutuhkan Tipologi ruang yang baru, yang lebih fleksibel dan juga nyaman bagi mereka demi memberi ke-efesienan bekerja yang lebih baik bagi Generasi Milenial.

Hal tersebut yang menghasilkan bentuk ruang yang tidak memiliki batas jelas antara ruang bekerja, makan maupun santai. Karena dengan begitu dapat membuat pekerja mengerjakan pekerjaan di ruang makan atau makan di ruang bekerja, tetapi ruang yang seperti ini lah yang sangat sesuai dengan Generasi Milenial karena di anggap feksibel bagi mereka.

Dalam mendesain ruang - ruang fasilitas Co-Living didapatkan beberapa fokus ruang yaitu ruang public food court area, Co-working, learning center dan Co-Living.

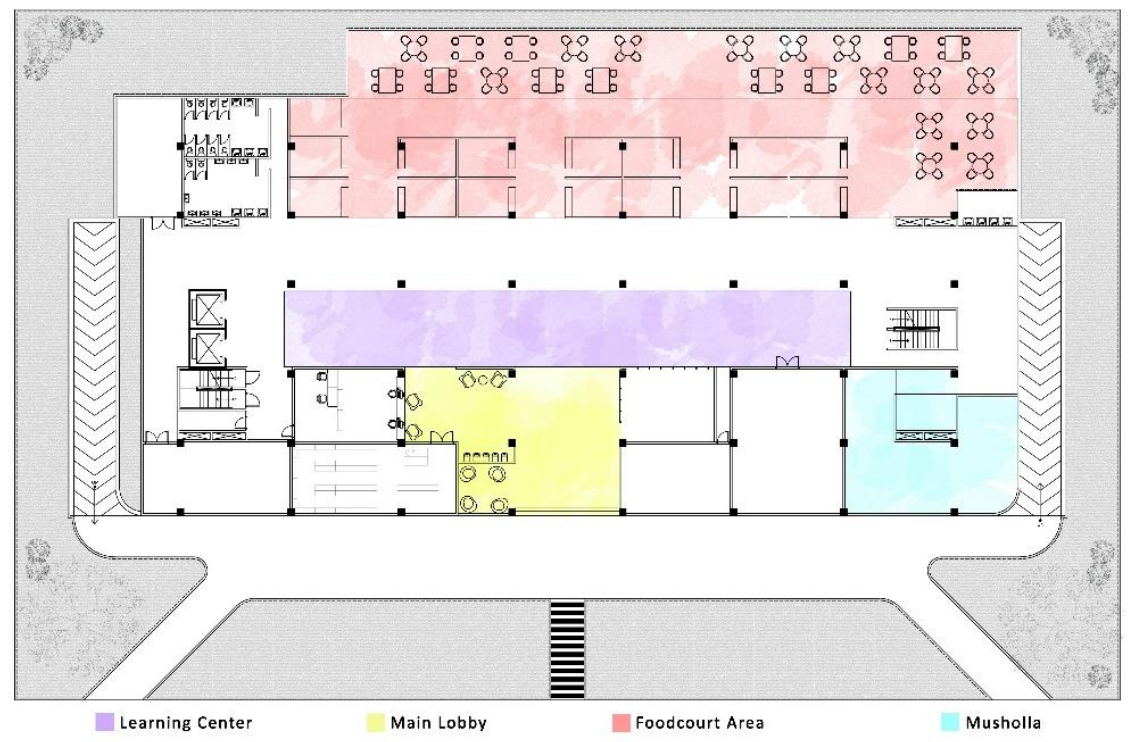

Gambar 4. Layout Lantai 1

Sumber: Penulis, 2019

Area makan berada di lantai dasar bersamaan dengan daerah penerimaan tamu untuk yang akan tinggal di Co-Living serta ruang penunjang nya. Dan juga di sertai kantor pengelola dan Mushola. Dengan mempertimbangkan kenyamanan suara dan privasi maka di letakan di belakang bangunan dan di bedakan ruang secara vertical dengan daerah Co-Working dan Learning Center. Area makan ini menunjang semua kebutuhan makan yang berada di dalam Gedung seperti Learning center, Co_Working, Co-Living.

Co-Working area menjadi sebuah solusi yang dibuat untuk memenuhi kebutuhan Generasi Milenial yang tidak suka dengan keadaan ruang kerja yang konvensional. Bersifat bergerak dan juga bebas terhadap aktifitas di dalamnya. Terdapat 2 ruang khusus yang sifatnya lebih 
private. Ruang kerja bersama yang di desain dengan mengutamakan kenyamanan setiap kelompok dan juga terdapat Zen Room yang bertujuan menjadikan ruang kerja yang lebih intensif terhadap setiap individu yang menggunakan ruangan ini. Ditujukan bagi mereka yang kurang nyaman dengan keramaian tetapi tetap mencari bentuk tipologi kantor yang berbeda dari pada kantor pada biasanya.

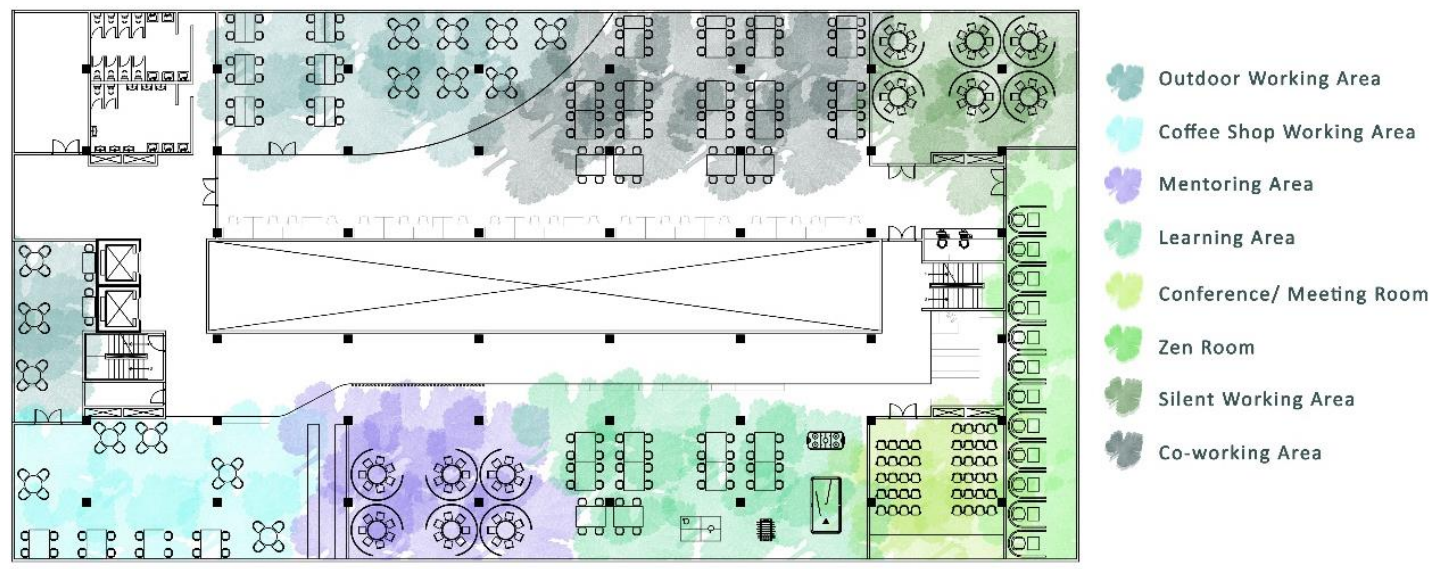

Gambar 5. Layout Lantai 2 (co-working area) Sumber: Penulis, 2019

Learning Center menjadi salah satu pendukung co-working area yang dapat membantu para Generasi Milenial untuk mendapatkan atau mengasah skill baru dengan tujuan menjadikan investasi skill bagi mereka untuk menunjang kebutuhan kerja mereka ke masyarakat luar. Learning Center ini juga di dukung dengan adanya beberapa mentor yang dapat mengajar di bidang nya, dan juga di tambah workshop yang dapat di adakan di ruang seminar untuk mempelajari skill baru bagi mereka yang tertarik mengikuti seminar atau workshop yang di adakan di learning area tersebut.

Co-Living merupakan solusi bagi mereka yang merasa penat atau mengalami stress lebih karena commuting menggunakan public transport dari daerah sekitar kota Jakarta menuju pusat kota. Hal ini sangat cocok di tapak ini karena terdapat persis di depan terminal bus antar daerah dan kota sekitar Jakarta. Dengan sistem yang dapat di sewa kan perhari, perminggu dan perbulan, dapat menjadi jawaban bagi mereka yang ingin beristirahat sejenak dari padatnya kendaraan umum yang mereka pakai untuk pulang ke kota asal.

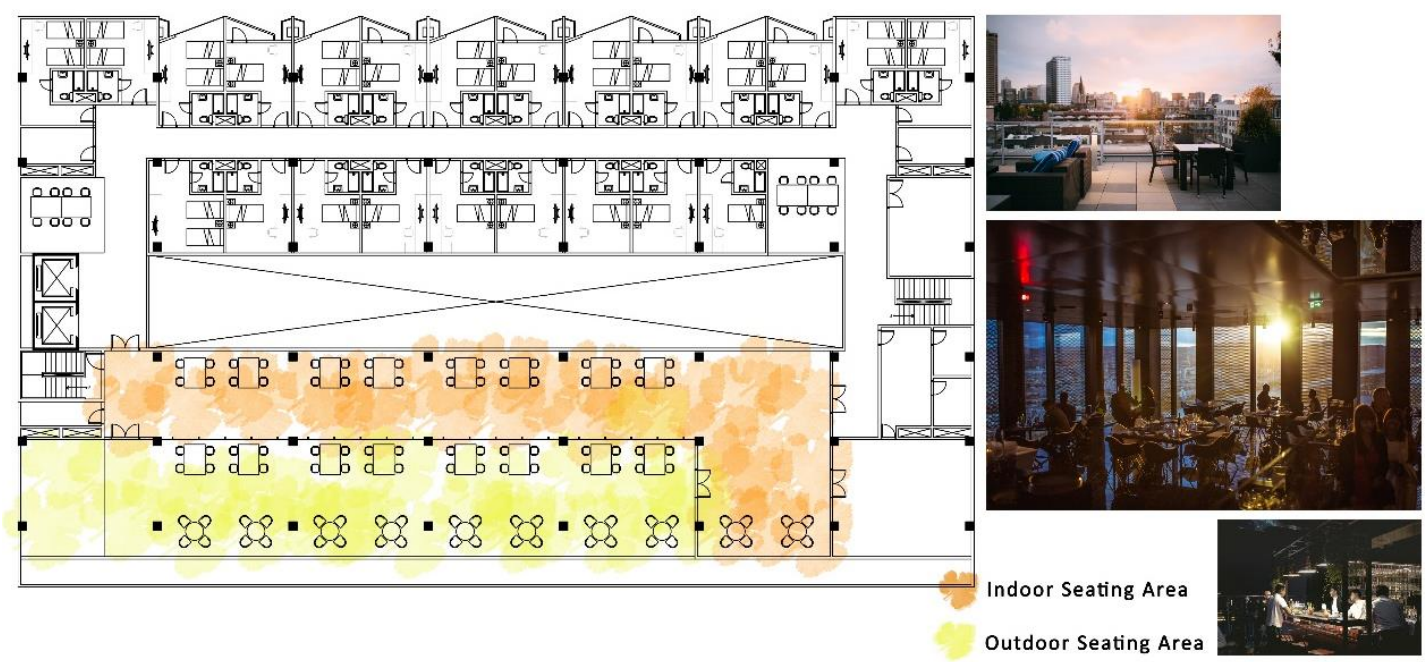

Gambar 6. Layout Lantai RoofTop Sumber: Penulis, 2019 
Restaurant rooftop merupakan area makan khusus untuk menunjang area co-living dengan tujuan memberikan pengalaman berbeda dengan area makan yang berada di bawah. Dengan penyelesaian arsitektur yang berbeda, dapat memberikan pengalaman ruang yang sifatnya lebih santai untuk menghabiskan waktu bagi mereka yang telah melakukan pekerjaan di siang hari.

Konsep bangunan yang di gunakan adalah kenyaman yang di sertai fasilitas yang dapat memenuhi kebutuhan para pengguna di dalamnya. Dengan tujuan memberikan kenyamanan karena tidak perlu memikirkan kebutuhan lain selain pulang ke kota asal karena semua kebutuhan kurang lebih sudah berada di dalam 1 bangunan.

Dibuat banyak bukaan dengan tujuan memberikan pencahayaan yang maksimal dan juga memberikan kelegaan ruang. Serta memberikan aliran udara yang baik untuk tujuan kesegaran bangunan dan para pengguna di dalamnya.

\section{KESIMPULAN}

Tempat Bekerja dan Tinggal untuk Milenial berperan sebagai wadah bekerja dan singah sejenak bagi mereka yang membutuhkan tipologi ruang kerja dan ruang istirahat bagi mereka yang memiliki masalah mengenai tempat tinggal yang jauh dari tempat bekerjanya. Masalah yang sering dijumpai oleh Generasi Milenials adalah kelengakapan ruang area bekerja, area makan dan area learning berdekatan, serta area tinggal dan juga refresing berupa restaurant yang berada di lantai atap. Sehingga proyek ini menjawab bentuk Tipologi yang di harapkan menjadi solusi bagi Generasi Milenials.

Proyek ini diharapkan dapat memberikan solusi bagi kaum milenial untuk mendapatkan akomodasi ruang kerja yang mereka butuhkan, serta dapat menjadi solusi lebih bagi mereka yang membutuhkan pelajaran tentang soft skill yang di butuhkan mereka, khususnya bagi kaum milenial dapat memjukan ekonomi dengan tempat dan waktu mereka menjalankan usaha ekonomi secara efesien dan ekfektif.

\section{REFERENSI}

A.R. (2018). Karakteristik Generasi Millennial di Dunia Kerja. Diunduh 5 maret 2019 https://www.hitsss.com/karakteristik-generasi-milenial-di-dunia-kerja/

Badan Pusat Statistik (2014) Statistik komuter jabodetabek. Diunduh 5 maret 2019 https://media.neliti.com/media/publications/48476-ID-statistik-komuter-jabodetabek2014.pdf

Burgess, J. (2008). Managing the new workforce, generation Y (Milenial). Red Fusion. Diunduh 4 maret $2019 \mathrm{http}: / /$ www.redfusion.com/arc_managing_generation_Y_milenial.htm

Ede, L. \& Lunsford, A. (2000) Some Millennial Thoughts about the Future of Writing Center. Diunduh 6 maret 2019 https://www.jstor.org/stable/43442099?seq=1\#page_scan_tab_contents Erickson, T. J. (2012). The Milenial. RSA Journal vol. 158, no. 5550, 22-25

Koolhas, R., \& Mau, B. (1995). S,M,L,XL. Rotterdam: 010 Publishers

Moneo, R. (1978). On Typology. Oppositions, 22-45

Kaplan, C. (2000) Millennial Class. Diunduh 5 maret 2019 https://www.jstor.org/stable/463227?seq=1\#page_scan_tab_contents

Lourenco, A. P. (2017) Teaching and Working With Millennial Trainees: Impact on Radiological Education and Work Performance. Diunduh 10 maret 2019 https://www.sciencedirect.com/science/article/pii/S1546144016304872

Tsukamoto, y., \& Kaijima, M. (2010). Behaviorolgy. New York: Rizzoli 
